\title{
GAMIFIED ASSESSMENT OF PRAGMATICS COMMUNICATION DEFICIENCIES IN PATIENTS WITH FIRST EPISODE PSYCHOSIS (FEP)
}

\author{
Polyxeni Fakitsa ${ }^{\mathrm{a}, \mathrm{b}}$, Eugenia I. Toki ${ }^{\mathrm{b}}$, Andreas Karampas ${ }^{\mathrm{a}}$, Petros Petrikis ${ }^{\mathrm{a}}$ \\ a Department of Psychiatry, Faculty of Medicine, School of Health Sciences, University of loannina, loannina, Greece \\ b Laboratory of New Approaches in Communication Disorders, Department of Speech \& Language Therapy, School of Health Sciences, University of loannina, Ioannina, Greece
}

\section{ABSTRACT}

People with schizophrenia have difficulties understanding non-literal speech (i.e. metaphors, metonymies, proverbs, humour). Literature reports $80 \%$ of patients with schizophrenia lagging respectively to control groups. Clinical environments using gamification (i.e. elements from game design in different processes) may enhance assessment by integrating immediate and rapid elements in a pleasant, motivating and engaging environment. The purpose of this study was to evaluate pragmatics deficiencies in patients with First Episode Psychosis (FEP) using gamification. The sample consisted of 80 individuals (40 FEP patients:- M:24, F:16, 40 individuals with no psychiatric history). Patients and controls were matched by age $(31,438 \pm 9,945)$, gender, educational and IQ level. The evaluation tool was developed based on Pragmatic elements for Greek on a gamified electronic procedure, consisted of 25 multiple choice questions, examining the following language features:(a) every-day life situations, (b) story comprehension on real news, (c) figurative language (idioms, metaphors and proverbs), (d) sense of humour, (e) emotions' perception, (f) counterfactual comprehension, and (g) language aspects (pronouns, and pragmatic connectors). It was administered to the sample of the study. Data was gathered and analysed with SPSS. The results of the study revealed statistically significant differences between patients and controls in the following variables: i) overall score points $(U=290, p=.000)$, and ii) completion time ( $(U=159$, $p=.000)$ and (iii) number of correct responses $(U=507,500, p=.004)$. Concluding, gamified evaluation tool detected Pragmatics Deficiencies showing statistically significant differences between patients and controls according to current digital trends and clinical developments.

\section{INTRODUCTION}

Pragmatics (proper use of language in any context including linguistic adjustments) is essential for communication (Owens,2014).

The lack of pragmatics competence is known as pragmatics communication deficit and has been documented in pathological populations. Individuals with schizophrenia have difficulties understanding non-literal speech (i.e. metaphors, metonymies, proverbs, humour). In particular, understanding metaphors, idioms, humour, irony and proverbs is disturbed in FEP patients, who have the tendency to interpret non-literal speech forms in a literal way (Turkstra et al, 2016).

$>$ Technology and digital games offer motivation and engagement opportunities in clinical settings. Gamification (elements from game design in different processes) comes to enhance clinical assessment by integrating immediate and rapid elements in a pleasant, motivating and engaging environment (Toki et al, 2018).

Aim of the study: to evaluate Pragmatics Communication Deficiencies in patients with FEP using gamification

\section{MATERIALS AND METHODS}

For the purpose of the study, a sample of 40 patients with FEP and 40 individuals with no psychiatric history were selected.

The experimental group (M:24, F:16) was monitored in Early Intervention Service in Psychosis at the University Hospital of loannina, Greece. Scales were measured in terms of:

$>$ Age

$>$ Intelligence Quotient (IQ)

$>$ Duration of Untreated Psychosis (DUP), and

$>$ Positive and Negative Syndrome Scale (PANSS).

positive symptoms subscale scores (PANSS-p)

negative symptoms subscale scores (PANSS- $n$ )

general psychopathological symptoms subscale scores (PANSS-g) total scores (PANSS-t).

The control group (M:24, F:16) was measured in terms of age and IQ.

The 2 groups were matched in gender, age, educational level and IQ.

Pragmatics" is a gamified e-assessment created in Kahoot!, based on APACS criteria (Arcara \& Bambini, 2016) evaluating aspects of pragmatics in Greek. It is consisted of 25 multiple choice questions divided into categories examining the language features (Toki et al, 2018): every-day life situations, story comprehension on real news, figurative language (idioms, metaphors and proverbs), sense of humour,

comprehension, and language aspects (pronouns, and pragmatic connectors.

"Pragmatics was applied in both groups evaluating language aspects recording measurements on

(i) Total Score Points,

(ii) Completion time, and

(iii) Number of correct answers across the Pragmatics elements.

Data was gathered and analysed with SPSS

\section{RESULTS}

Experimental group: Age: $31,43 \pm 9,94$, IQ: $108.2 \pm 7.14$, DUP:10.45 \pm 8.26

PANSS-p: 8.2 (0.6), PANSS-n:22.8 (6.7), PANSS-g: 16.5 (1.8), PANSS-t:47.5 (7.9)

Control group: $\quad$ Age: $32,23 \pm 8,70,1 Q: 107,9 \pm 8.25$

\begin{tabular}{|l|l|r|r|r|}
\hline \multicolumn{1}{|c|}{ Table 1} & \multicolumn{1}{|c|}{ Total Scorepoints } & Correct Answers & \multicolumn{1}{c|}{ Time (sec) } \\
\hline $\begin{array}{l}\text { - Measurements } \\
\text { by Groups }\end{array}$ & Control & $29.266,65 \pm 3.583,019$ & $23,00 \pm 1,633$ & $146,00 \pm 59,011$ \\
\hline \begin{tabular}{l}
-(Mean \pm SD) \\
\cline { 2 - 5 }
\end{tabular} & Experimental & $23.360,37 \pm 6.473,661$ & $21,60 \pm 2,193$ & $270,34 \pm 90,813$ \\
\cline { 2 - 5 } & Total & $26.313,51 \pm 5.988,161$ & $22,30 \pm 2,046$ & $208,17 \pm 98,511$ \\
\hline
\end{tabular}

Statistically significant differences were found between Experimental and Contro group:

i) Total Score Points $(U=290, p=.000)$,

ii) Completion time $(U=159, p=.000)$,

iii) Number of correct answers ( $U=507,500, p=.004)$

\begin{tabular}{|l|l|r|r|r|}
\hline \multicolumn{1}{|c|}{ Table 2} & \multicolumn{1}{|c|}{ Total Scorepoints } & Correct Answers & \multicolumn{1}{c|}{ Time (sec) } \\
\cline { 2 - 5 } $\begin{array}{c}\text {-Measurements } \\
\text { by Gender } \\
\text { •(Mean } \pm \text { SD) }\end{array}$ & Male & $25.224,67 \pm 6.596,866$ & $21,96 \pm 2,093$ & $223,97 \pm 101,394$ \\
\cline { 2 - 5 } & Female & $27.946,78 \pm 4.561,910$ & $22,81 \pm 1,891$ & $184,47 \pm 90,429$ \\
\cline { 2 - 5 } & Total & $26.313,51 \pm 5.988,161$ & $22,30 \pm 2,046$ & $208,17 \pm 98,511$ \\
\hline
\end{tabular}

Statistically significant differences were noted between genders:

- Males: There was a statistically significant difference in the performance between experimental and control group in the following variables:

i) Total Score Points $(U=110,000, p=.000)$ and

ii) Completion time $(\mathrm{U}=62,000, \mathrm{p}=.000)$.

Females: There was a statistically significant difference in the performance between experimental and control group in the following variables:

-i) Total Score Points $(U=37,000, p=.000)$,

-ii) Completion time ( $U=20,000, p=.000)$, and

-iii) Number of correct answers (U=61,500, $p=.011)$.

\section{CONCLUSIONS}

The gamified procedure detected Pragmatics Communication Deficiencies in FEP patients when compared to individuals with no psychiatric history. The control group was faster, more accurate with better total score than the experimental group.

Gamification e-assessment has a potential to be employed for diagnostic face to face \& telepractice procedures offering mutual benefits for clinicians and patients.

Gender Differences noted indicated that overall females responses on pragmatic skills are faster and more accurate than males.

This research may provide a basis for further study and investigation of the Pragmatics deficits in larger groups of patients with FEP, as well as different pathological populations and different age groups always in line with current developments.

\section{Indicative References}

Arcara, G., \& Bambini, V. (2016). A Test for the Assessment of Pragmatic Abilities and Cognitive Substrates (APACS): Normative Data and Psychometric Properties. Frontiers in Psychology, 7. doi: 10.3389/fpsyg.2016.00070

Carotenuto, A., Arcara, G., Orefice, G., Cerillo, I., Giannino, V., Rasulo, M., lodice, R., \& Bambini, V. (2017). Communication in Multiple Sclerosis: Pragmatic Deficit and its Relation with Cognition and Social Cognition. Archives of Clinical Neuropsychology, 1-12. doi:10.1093/arclin/acx061 